\title{
ФОРМИРОВАНИЕ МЕТОДИКИ АНАЛИЗА МОДЕРНИЗАЦИИ НА ПРЕДПРИЯТИИ
}

\author{
(C) 2019 Никулина Екатерина Юрьевна \\ специалист по УМР кафедры «Экономики, организации и стратегии развития предприятия» \\ Самарский государственный экономический университет, Россия, Самара \\ Email: katerina_nikulina@list.ru
}

Модернизация выступает жизненно необходимым механизмом для выживания компаний в условиях изменяющейся среды. Анализ состояния предприятия является одним из первых этапов проведения модернизации. Автором разработана методика анализа необходимости, хода и направленности модернизации предприятия как результат проведенного исследования существующих подходов к анализу деятельности предприятия. Предложенная методика предоставляет возможность тщательного изучения и оценки состояния предприятия и его положения на рынке, необходимость, ход и направленность модернизации предприятия, и, как следствие, обоснованно сформировать проект модернизации.

Ключевые слова: модернизация, анализ состояния предприятия, машиностроительная отрасль, технология стратегического анализа.

Процесс осуществления изменения модернизационного характера диктует предприятиям необходимость оперативно решать проблемы, связанные с определением необходимости модернизации, выбора момента времени её осуществления, формирование её направленности, ориентиров. Многие из них должны быть решены в процессе анализа состояния предприятия и предпосылок проведения модернизации.

В экономической литературе выделяются различные методы и методики анализа, которые позволяют провести в том или ином «срезе» детальный анализ деятельности предприятия. Однако, они не вполне соответствуют оценке необходимости, хода и направленности процессов модернизации на предприятии, поэтому необходима детальная характеристика и построение методики.

Во многом, несоответствие уровня развития средств труда, методов организации и управления производством современным требованиям и является причиной возникновения необходимости модернизации предприятия. Именно анализ внешней среды предприятия должен позволить сформулировать цели и направления модернизации. При этом важна не только оценка текущей ситуации, но и исследование перспективных тенденций. При построении методики следует учитывать и специфику машиностроения.

Улучшение финансово-экономических пока- зателей предприятия в результате модернизации может быть достигнуто за счет изменений как предприятия в целом, так и за счет отдельных, локальных изменений в отдельных сфеpax деятельности предприятия. Анализ должен вскрыть «узкие» места в деятельности машиностроительного предприятия в первую очередь нуждающееся в модернизации. Для построения методики оценки необходимости хода и направленности модернизационных процессов на предприятии целесообразно проанализировать существующие подходы к анализу деятельности предприятия.

Большое количество авторов для характеристики состояния предприятия, его инновационного потенциала широко используют понятия «технический уровень», «технико-экономический уровень», «организационно-технический уровень» и др. Под техническим уровнем производства понимается характеристику развития средств производства и в первую очередь, орудий труда. Г.И. Хотинская и Т.В. Харитонова выделяют понятие «научно-технический уровень производства [7]. Технико-организационный уровень - достигнутый уровень развития средств и способов производства, методов организации и управления [3, 4]. С.И. Кузнецов утверждает, что организационно-технический уровень производства характеризует» достигнутый предприятием уровень развития средств производства, форм и методов организации управления» [5]. 
Характеризуя вышеназванные подходы, можно ответить, что во многом подходы по определению и оценке инновационного потенциала близки к исследованию модернизационных процессов. Нельзя строить проекты модернизации предприятия без учета сформированных инновационных стратегий без взаимосвязи их с инновационной деятельностью предприятия.

Рассмотрим существующие методы и алгоритмы стратегического анализа, которые также позволяют сделать выводы и рекомендации на длительный, стратегический период, а также подходы по его проведению и изучим возможность их использования применительно к исследованию модернизационных процессов.

В работах экономистов выделяются различные методы анализа окружающей среды (SWOT- анализ; модель пяти конкурентных сил M. Портера, СтАР- анализ или анализ разрывов, диаграмму «Ишикава»). Используемые в этих методах оцениваемых параметров формулировки, например, «высокая компетентность», «адекватные финансовые источники» и др. не позволяют установить для них в практической деятельности однозначных количественных характеристик и допускают многоаспектное толкование.

C точки зрения анализа модернизационных процессов на предприятии большой интерес представляет технология стратегического анализа. В её рамках обычно выделяют анализ внешней среды, подразделяя ее на макроокружение и микроокружение, и анализ внутренней среды предприятия.

При анализе макросреды авторы по-разному рассматривают состав групп (компонент) показателей. А.Н. Хориным, В.Э. Керимовым выделяются следующие группы: экономика, политика, законодательство, технологии, состояние социальных отношений народонаселения и экологии в стране, регионе [6]. Однако конкретные показатели они выделяют только по компоненте «экономика»: величина валового национального продукта, уровень безработицы, темпы инфляции и др. По остальным компонентам предлагается оценивать качественные параметры.

При анализе внутреннего состояния предприятия представляет интерес состав конкретных показателей, используемых исследователями при оценке различных уровней производства (технико-организационных, организационно- технических и др.), а также инновационного потенциала предприятия [5].

Для характеристики организационнотехнического уровня С.И. Кузнецов использует более обширную систему показателей, выделяя в ней 2 группы: зависящие (внутренняя среда) и независящие от деятельности предприятия (внешняя среда), в которые входят отдельные подгруппы, например, применительно к внутренней среде: показатели, характеризующие уровень техники, технологии, уровень организации и управления производством, социальные условия, работы коллектива [5].

При оценке инновационного потенциала В.В. Валиева и А.Г. Максимова выделяет 5 укрупненных блоков показателей (продуктовый, функциональный, ресурсный, организационный, управленческий), в каждом из них от 2 до 12 качественных параметров. Оценка инновационного потенциала организации осуществляется путем сравнения качественных характеристик отдельных групп с нормативными требованиями, устанавливаемыми самой организацией [1]. Р.Р. Вьюнова выделяет ресурсный, результативный, целевой, системный. При этом только в ресурсном рекомендуется производить оценку подходы для оценки инновационного потенциала предприятия различных компонент. В целом, во всех методах большое значение имеет качественная оценка [2].

Алгоритм анализа необходимости, хода и направленности модернизации предприятия анализа должен различаться в зависимости от разных типов машиностроительных предприятий, поэтому начальным этапом анализа является их типизация. Можно выделить различные её признаки, но целесообразно выделить два из них: признак самостоятельности, определяемый наличием или отсутствием зависимости от других предприятий, признак значимости, определяемый способностью получения поддержки региональных или федеральных правительственных структур. Соответственно, по первому из них можно выделить самостоятельное предприятие, входящее в состав интегрированной (корпоративной) структуры. По второму - предприятие, не имеющее региональной и федеральной значимости, предприятие, имеющее региональную значимость, предприятие, имеющие федеральную значимость. Критерием в этой группировке должна являться возможность предприятия использовать поддержку 
соответствующего уровня управления. Первый тип предприятия (самостоятельное, не имеющее региональной и федеральной значимости) можно определить как чисто рыночный, второй, имеющий региональную и федеральную значимость) - как структурообразующий. Для рыночного типа предприятий анализ макросреды должен осуществляться в целом по традиционному алгоритму. Для двух других групп предприятий анализ макросреды должен проходить несколько иначе. Для них также необходимо изучение и другой группы факторов: прогнозируемой динамики госзаказа, тенденций политики и импортозамещения, возможностей и ограничений, определяемых санкционными ограничениями.

Примерно по аналогичной схеме будет осуществляться и анализ микросреды. Для предприятий рыночного типа состав факторов для анализа, и соответствующих показателей, относительно традиционен. Для структурообразующих предприятий - дополнительно изучать позицию управляющей компании интегрированной (корпоративной) структуры по отношению к предприятию-инициатору модернизации, внутрикорпоративный контур-покупателей, поставщиков, конкурентов, уровень внутрикорпоративной конкуренции, финансово-экономическое положение интегрированной (корпоративной) структуры.

Позиция управляющей компании во многом определяет и доступ к заказам и ресурсам интегрированной компании. Если рыночное окружение у предприятий разных типов различается, то внутренняя среда состоит из схожих составляющих. Начальным элементом анализа внутренней среды является исследование финансовоэкономического состояния. Оно изучается на основе традиционных алгоритмов оценки динамики основных технико-экономических показателей деятельности предприятия и показателей финансового состояния.

Принципиальным моментом в предлагаемой методики является наличие этапа, предусматривающего группировку и анализ процессов производственной деятельности машиностроительного предприятия. Существуют различные варианты группировок таких процессов. Наиболее общим является деление производственных процессов в машиностроении на основные, вспомогательные и обслуживающие, а также на стадии производства: заготовительные, обрабатывающие, сборочные. При анализе необходи- мости, хода и направленности модернизации представляется целесообразным сгруппировать эти процессы следующим образом: группа заготовительных, вспомогательных, обслуживающих процессов (производств), группа обрабатывающих процессов (производств) и группа сборочных процессов (производств).

В рамках каждого блока производств целесообразно исследовать следующие составляющие: собственное производство, поставщики, организацию и управление. В первом случае (собственное производство) изучаются показатели работы заготовительных, вспомогательных и обслуживающих подразделений предприятия: объем производства, качество продукции, себестоимость, используемые материалы и их альтернатива и др. Вторая составляющая - исследование поставщиков - связана с тем, что в любом случае машиностроительное предприятие часть полуфабрикатов и комплектующих закупает на рынке. Следует учитывать при формировании проекта модернизации предприятия, что в машиностроении качество конечной продукции во многом определяется качеством поставляемых материалов, полуфабрикатов, комплектующих.

Одним из завершающих этапов предлагаемой методики является формирование проекта модернизации предприятия и его обоснование. В случае уже происходящих модернизационных изменений контроль и корректировка его реализации с учетом исследованных и постоянно меняющихся характеристик окружающей среды. При этом следует учитывать, что обоснование проектов модернизации для разных вышеназванных типов предприятий будет несколько различаться. Это связано с тем, что если для предприятий 1-го типа обоснование проекта должно основываться исключительно на рыночных принципах, то для предприятий типа помимо рыночных могут учитываться и внерыночные характеристики, связанные либо с их значимостью, либо с возможностями интегрированных корпоративных структур. С практической точки зрения это могут быть, например разные процентные ставки под кредитные ресурсы.

Заключительным этапом анализа является формирование выводов и предложений по модернизации предприятия. Данная методика позволяет достаточно подробно оценить состояние предприятия и его положение на рынке, необходимость, ход и направленность модернизации предприятия, обоснованно сформиро- 


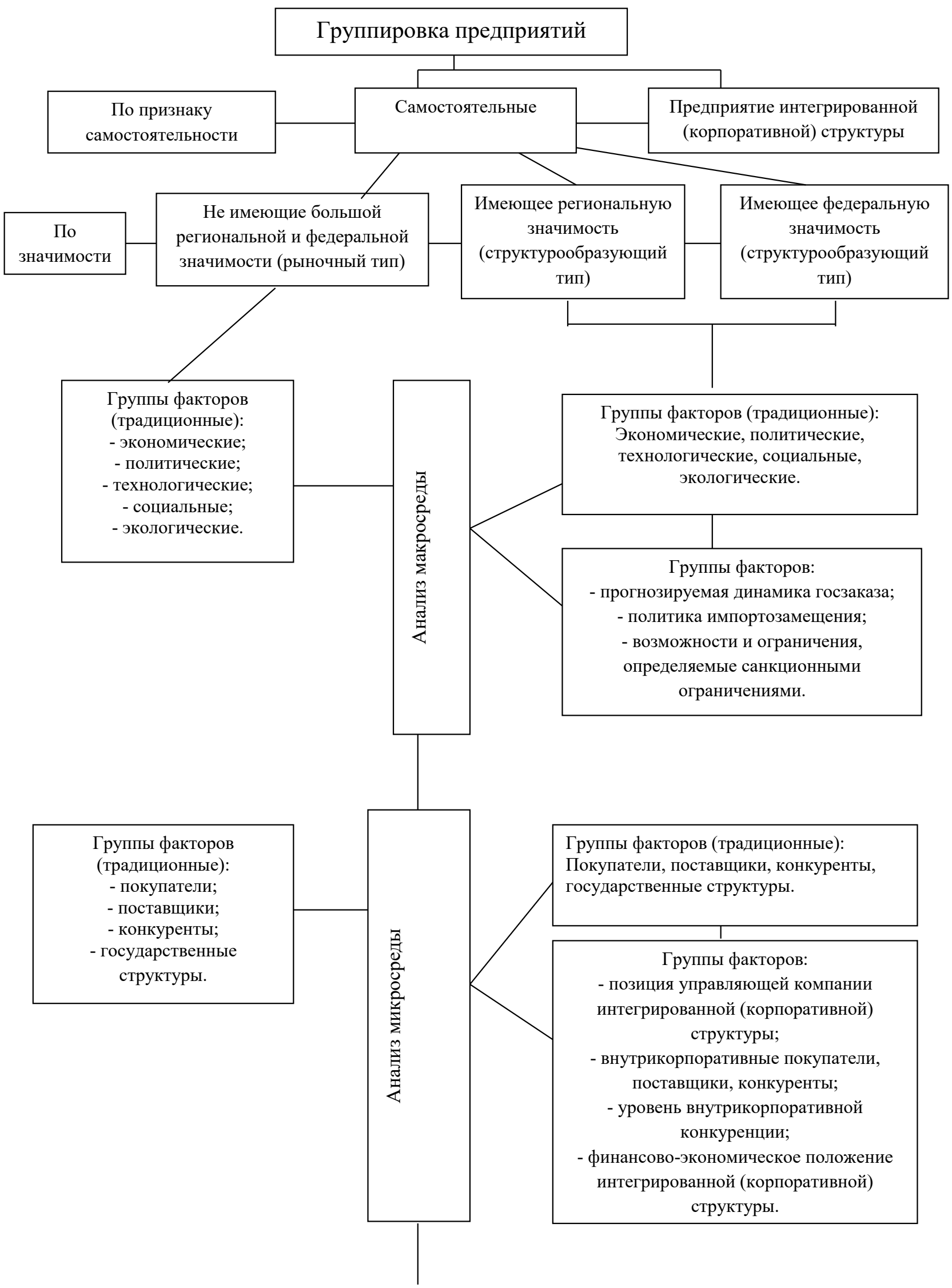




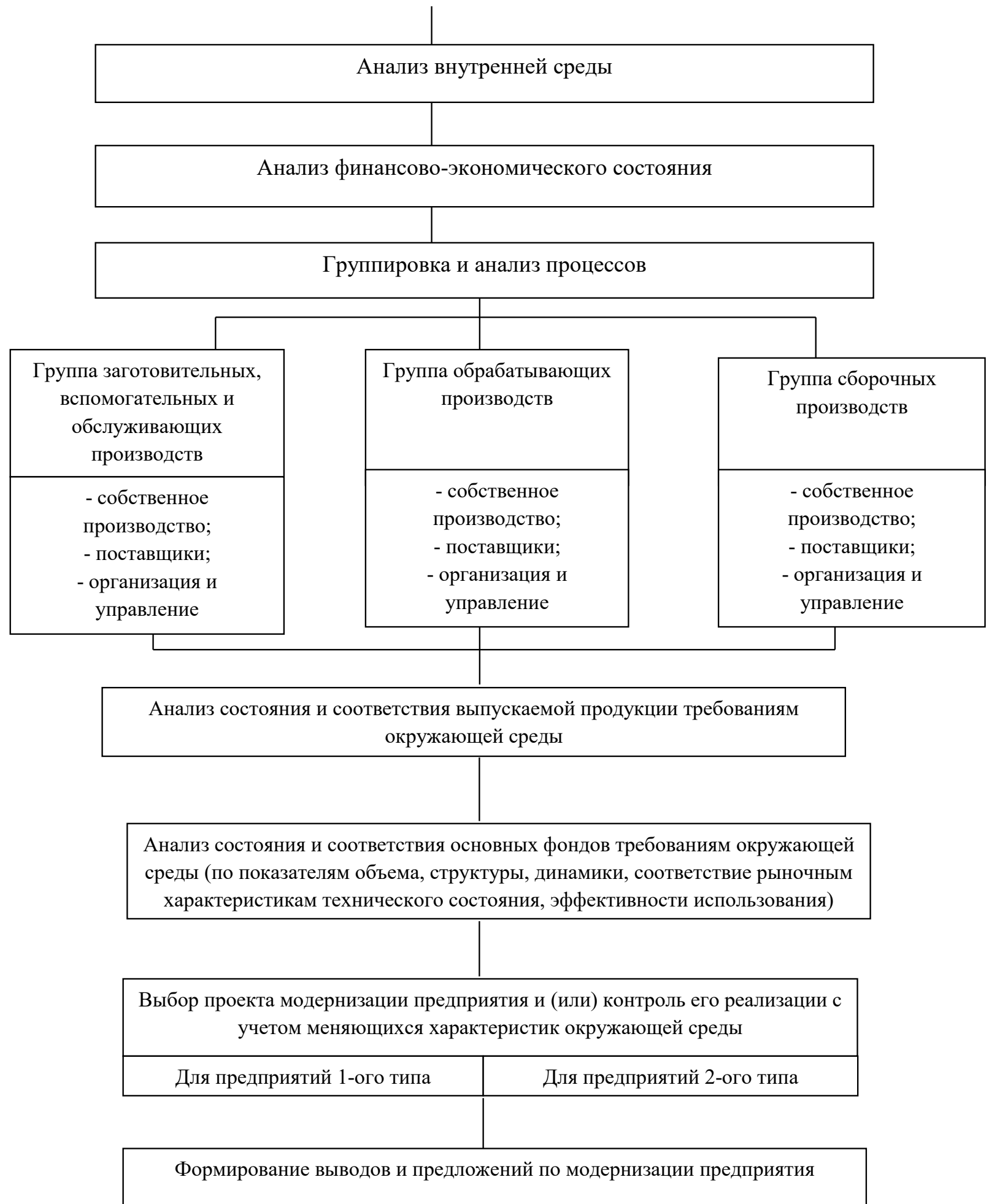

Рuc. 1. Методика (предлагаемая) анализа необходимости, хода и направленности модернизации предприятия. 
вать проект модернизации. Проведение анализа окружающей предприятия среды позволит также контролировать ход реализации проекта модернизации предприятия, с учетом его возможных корректировок.

Данная методика позволяет достаточно подробно оценить состояние предприятия и его положение на рынке, необходимость, ход и направленность модернизации предприятия, обоснованно сформировать проект модернизации. Проведение анализа окружающей предприятия среды позволит также контролировать ход реализации проекта модернизации предприятия, с учетом его возможных корректировок.

\section{Библиографический список}

1. Валиева В.В., Максимова А.Г. Проблемы государственной поддержки малого предпринимательства // В сборнике: Управление Экономический анализ Финансы Сборник научных трудов. Под общей редакцией И.Р. Кощегуловой.2017. С. 244-249.

2. Вьюнова Р.Р. Оценка инновационного потенциала предприятия. В сборнике: Экономика. Теория и практика. Перспективы XXI века. Материалы II международной научно-практической конференции.2015. С. 2430.

3. Забелин А.Г., Квитченко К.Н. Анализ системы показателей технико-организационного уровня развития производства как основа конкрентных преимуществ промышленного предприятия // Сегодня и завтра Российской экономики.- 2012.№ 52. С. 161-169.

4. Забелин А.Г., Квитченко К.Н. Основные проблемы формирования системы контроллинга для целей машиностроительного бизнеса Московского региона. // Научное обозрение. Серия 1: Экономика и право. Издательство: Экономическое образование (Москва). № 6. 2011. С. 157-166.

5. Кузнецов С.И. Совершенствование анализа организационно-технического уровня производства на предприятиях различных форм собственности // Экономический анализ: теория и практика.2009. № 35. С. 8.

6. Хорин А.Н., Керимов В.Э. Стратегический анализ: учебное пособие.- М.: Эксмо.- С. 90.

7. Хотинская Г.И. и Т.В. Харитонова. Анализ хозяйственной деятельности предпрития на примере предприятия сферы услуг / Москва, 2007. 